\title{
Appendix \\ LASSO Evaluation, Questions and Scoring Kit
}

\section{Chapter 3}

Look before you leap; here are seven searching questions to answer before you decide where to extend or expand:

1. What exactly is the problem that you're solving for buyers? And why would consumers look to you to solve it?

2. Is your brand closely linked to a specific product set or to a more general idea? If it's the latter, what qualifies your brand to take ownership of that broader idea?

3. Are you big enough and well known enough to extend or expand? What makes you more than a "fad" in the minds of those who buy into you?

4. What do consumers want more of from your brand, if anything? Will the association make sense to them? Will it change their world for the better?

5. How does your brand fit into the lives of your core consumers? What latitude will they give the brand to take up more space in their lives? 
6. Do the dynamics of the sector(s) you are looking to expand into warrant your presence?

7. How will you counter the downsides of being more widely available?

\section{Your Turn}

Professor Kevin Keller's book Strategic Brand Management: Building, Measuring and Managing Brand Equity includes a very good Brand Extendibility Scorecard. I was so taken with his idea that I've adapted it for the LASSO Model using a spider web evaluation tool. We'll build one for your brand over the course of the book.

Were you able to select a Lateral score that best matches your brand? Good! Jot it down in the margin for easy reference. Once you're ready, turn to the next section and get ready to evaluate your brand from an Addictive perspective, the second element of the LASSO Model.

\section{Chapter 4}

Keep them coming back; here are seven searching questions to judge whether you have a highly addictive brand:

1. What more does the brand deliver that people want escapism, distraction, adventure, authority?

2. Will consumers see the connections between the various expressions of your brand? How will you direct them from one activity to another?

3. Do you understand the overall playbook? On what journey are you taking consumers? With what part of that journey are you involved? 


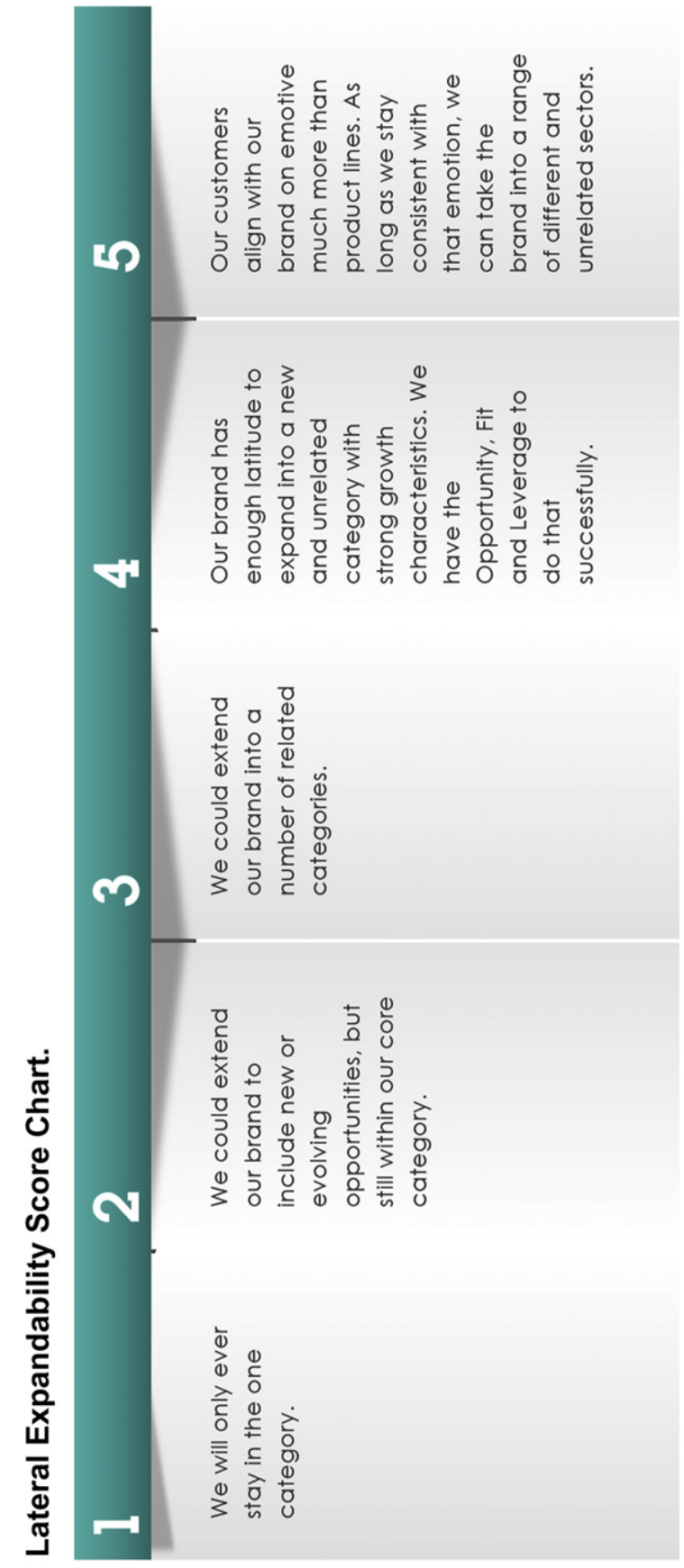


4. How long do you want to keep customers buying? Is your involvement with the brand tied to a specific time frame or project, or is it longer?

5. Does your program have the best mix of frequency, intensity, access, and surprise?

6. What's your exploration bonus?

If you are the brand owner, is your core business inherently profitable? How dependent are you on ancillary revenue to hit your growth targets? And therefore, how big does your licensee community need to be?

\section{Your Turn}

In the previous chapter, we asked you to rate your brand's ability to extend or expand. Now let's do the same thing for Addictiveness. Please think about your answers to the seven questions we just asked and score your brand on its addictive potential. Once again, there are no right or wrong answers. Some brands will feel that they are not addictive and have no interest in becoming addictive. Others will see opportunities to make a lot more frequently recurring income. Choose the number that best describes your brand's potential to keep buyers coming back for more. We'll come back and get this number later (see next page).

Were you able to select an Addictive score that matches your brand? If so, great job! Let's keep the momentum going. Now that you're assessed how Lateral and Addictive your brand is, when you're ready, turn to the next section and get ready to evaluate your brand from a Storied perspective, the third element of the LASSO Model. 


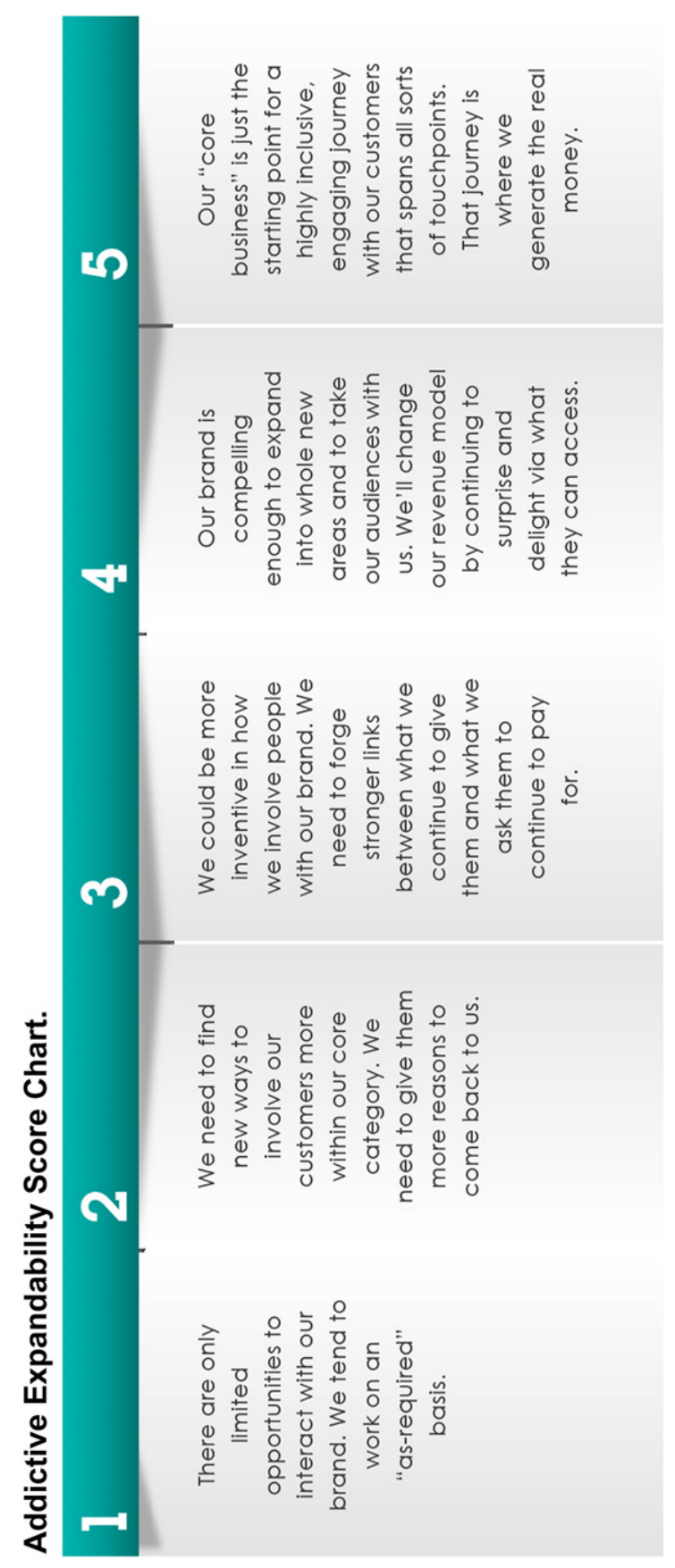




\section{Chapter 5}

Inviting people in; here are six searching questions to assess the state of your story:

1. What do people most want to know about that pertains to what you do? If you work in a high-interest sector, how will you compete for attention? If you have a low-interest brand, what can you do, say, stand for, or talk about that will get people leaning toward you?

2. How are you expanding how people perceive your brand through storytelling?

3. Where will you tell your stories, and how will you use the channels to shuttle between the immediate and your wider world?

4. What role do customers have in helping to shape and influence your story?

5. How will new partners change your storytelling? How will their stories blend with yours?

6. How have you connected your storying to your selling? How accurately can you measure how and when conversion occurs? Which of your storylines are most profitable?

\section{Your Turn}

Is your brand building its story into a rich mythology? Please score your brand on how powerfully you think your brand is framed in the minds of consumers below. Once again, there are no right or wrong answers. Some brands will feel that storytelling is just part of how they explain themselves; others will see it as a way to continually redefine and refresh everything they represent. Choose the number that best describes how your brand connects and explains its actions and viewpoints. We'll come back and get this number shortly. 


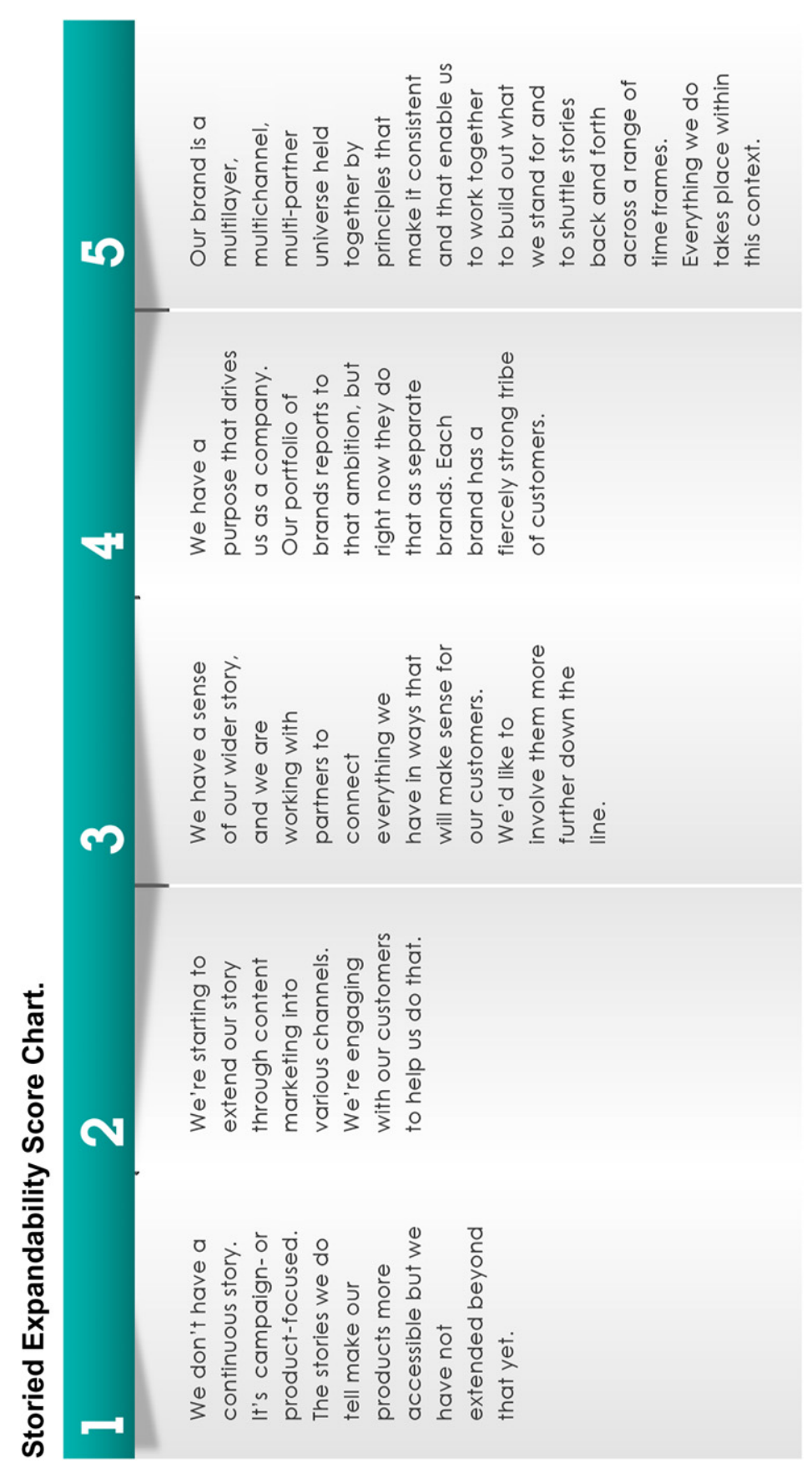


What is the Storied score that matches your brand? Mull it over and then decide. You've come a long way! I hope you have been diligent and honest in evaluating your brand in the LASSO Model along the Lateral, Addiction, and Storied attributes. When you're ready, turn to the next section and get ready to evaluate your brand from a Scalable perspective, the fourth element of the LASSO Model. You're almost there!

\section{Chapter 6}

A framework for scale; here are six questions on size and scope:

1. How much do you want the brand to be worth? - It's surprising how seldom this question gets asked by marketers and those building brands, and yet it's critical because it not only defines the value of the brand for the business, but also frames the level of investment that the business is prepared to make in the brand. You can define brand worth in a range of ways of course - by revenue, by margin, by percentage of total market share, or by book value. The important thing is that you have a number that defines success which forms the basis for what you bankroll.

2. What are your critical assets? - What are the key ideas that you need to own, and therefore be able to defend, if you are to achieve your plans? What IP and protection will you build into your products, for example, that enables them to be less susceptible to counterfeiting? What allowance have you made for including the contributions of others in your new product development, and how will you define what you simply incorporate versus that for which you decide to charge? How will you value those owned assets in terms of the returns you expect from them, and will that contribution be transparent to decision makers so that they can judge asset effectiveness? 
3. Over how many sectors can and should your brand stretch? - It's important to have an overview of the potential stretch of the brand. How do consumers see you as a brand that owns an idea, or one that occupies a specific sector? What do they value you for, and how elastic is that? In other words, what mandate do you have to extend or expand, or do you even have one? With traditional licensing deals for example, so many brands think about expanding on an offer-by-offer basis rather than consciously planning where the next brand interaction sector might be from the "big picture" down. My experience and research shows that successful brands know how they will expand, where and with whom, and have supporting research for doing so. They also need to be aware of the contribution to overall worth that they wish to derive from within each sector. In other words, they need to consider not just the financial returns but also what expansion might mean for overall brand presence and value. They need to be able to strategize top-down and bottom-up. Critically, they should define "trip points" in terms of reach and revenue in their strategy that decide when they should consider casting their net wider or deeper.

4. Across how many countries can your brand travel? - If your brand is ranged across multiple countries or regions, are you doing this to grow the brand you have, or as part of a broader expansion strategy? Entrepreneur Media, Inc. has taken an approach of extending its core business, its publishing, via licensing and joint venture to countries outside the United States including India, Mexico, the Philippines, and South Africa. By gaining a presence in these regions, it enables Entrepreneur to offer additional products and services to its consumers in those markets. As Bill Shaw, Entrepreneur's President said,

The way we look at it, advertising is our main revenue stream but licensing allows us to diversify and 
create a monthly annuity so we're not so reliant on media which can be very unstable. Licensing also offers a way we can extend our brand so more people can see it.

It's vital that you plot where you will expand market participation and in what order. This should be led by market appetite, but you should also factor in potential market size, uptake rates, the success paths of others in each market, the levels of competition in the sectors you are looking to expand into, and of course whether you will be able to achieve benchmarked levels of margin as you go.

5. Over what period of time can you afford to grow? - It's important to know the time frames within which you want to achieve growth. Are you using SMART - Specific, Measureable, Achievable, Relevant, Time-oriented — objectives to achieve your goals? Again, while that may seem obvious, a lot of brands don't think through the implications of those specifics in terms of forward-planning, resourcing and, particularly, runways. The key determinant here will be market demand. How quickly will you need to expand in order to fulfill consumer interest, and what dependencies will you put around extending into a particular market?

6. What resources are available to you? - Where will the growth come from? After determining where to play, you need to determine how you will win. This requires you to take a look at your internal capabilities and priorities. What part of the expansion can you do and have the capacity to do? Based on this you will need to assess what parts need to come from external resources. This could include sourcing, where you will do the marketing and sales; acquisition, where a new company will be integrated in to take on this role; or, via licensing, where you can leverage the competencies and bandwidth of third parties to execute those parts that complement what your team is going to do. 
By developing an overall plan of what your expanded brand looks like; and a strategy for how, where, and when that will roll out; and with what packets of investment, you have the opportunity to empower their team members to work together, to judge every opportunity on its merits, and to better connect opportunities within the context of achieving your overall goals for brand worth.

\section{Your Turn}

OK, by this point you know the drill. Time to assess how Scalable you need to be as a brand and how far consumers will allow your brand to go. Please think about your answers to the six questions above and score your brand on how you intend to take your brand forward and what that will mean for your availability on the chart below. As always, there are no right or wrong answers. Some brands will feel that there are still plenty of room for them to grow; others will see that a more focused approach will enable them to gather the best returns. Choose the number that best describes how your brand expands geographically. We'll come back and get this number soon (see next page).

Does a particular Scalable score represent your brand well? Once you have settled on the right number, you are ready to contemplate the final LASSO element, that of your brands degree of Own-ability. Up to now you've run a steady race, contemplating how Lateral, Addictive, Storied, and Scalable your brand is today. If you're feeling a little unsure of yourself, please trust the process and plow ahead. If you're feeling pretty good, then let's roll forward to Own-able, the final element of the LASSO Model. Ready? Then, let's get started. 


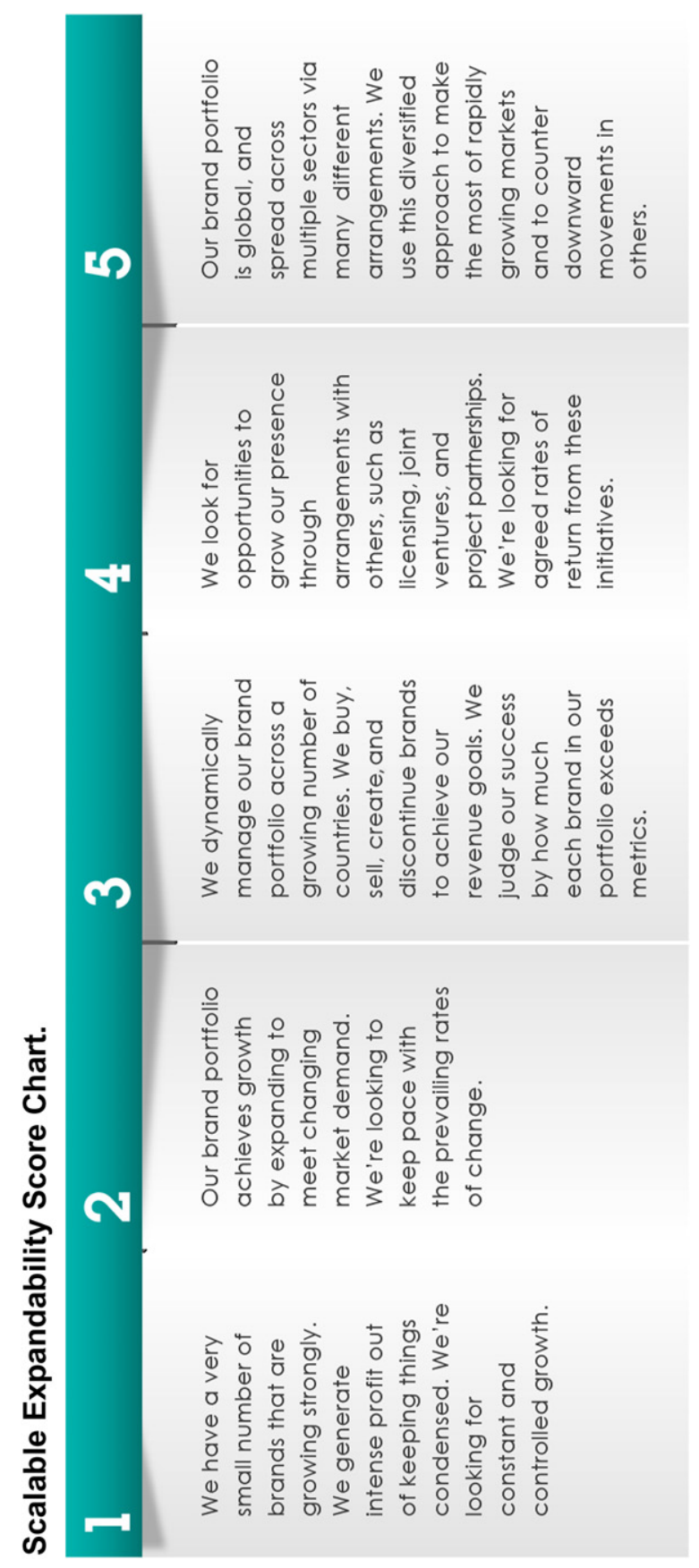




\section{Chapter 7}

Understand what you need to have control of; here are seven searching questions to judge whether you have a highly ownable brand:

1. What structure do you need to deliver your idea to its full potential? How much of that do you need to have a stake in to make your goal a reality?

2. What do you need to own to succeed?

3. What do you expect to own in the next five years, what do you expect to lose or share, and what do you expect to be copied or to become industry standard?

4. Will your ownership model change over the next five years, and how will that affect what's own-able? What's not and what could be own-able?

5. Where are the revenue streams going? For what will you be remunerated, and for what else will customers be willing to pay going forward?

6. How important is your IP to you? How have you valued that IP? What weaknesses exist in your IP? How and when can competitors copy you?

7. Which is more important in your sector, speed-to-market or ownership of market?

\section{Your Turn}

You've come to an exciting place. In the course of this book so far, I've asked you to rate your brand on its ability to extend or expand, its addictive potential, the nature of your story, and the scale at which you are most effective. Now let's do the same thing for Own-able. Please think about your answers to the seven questions above, and score your brand below. 


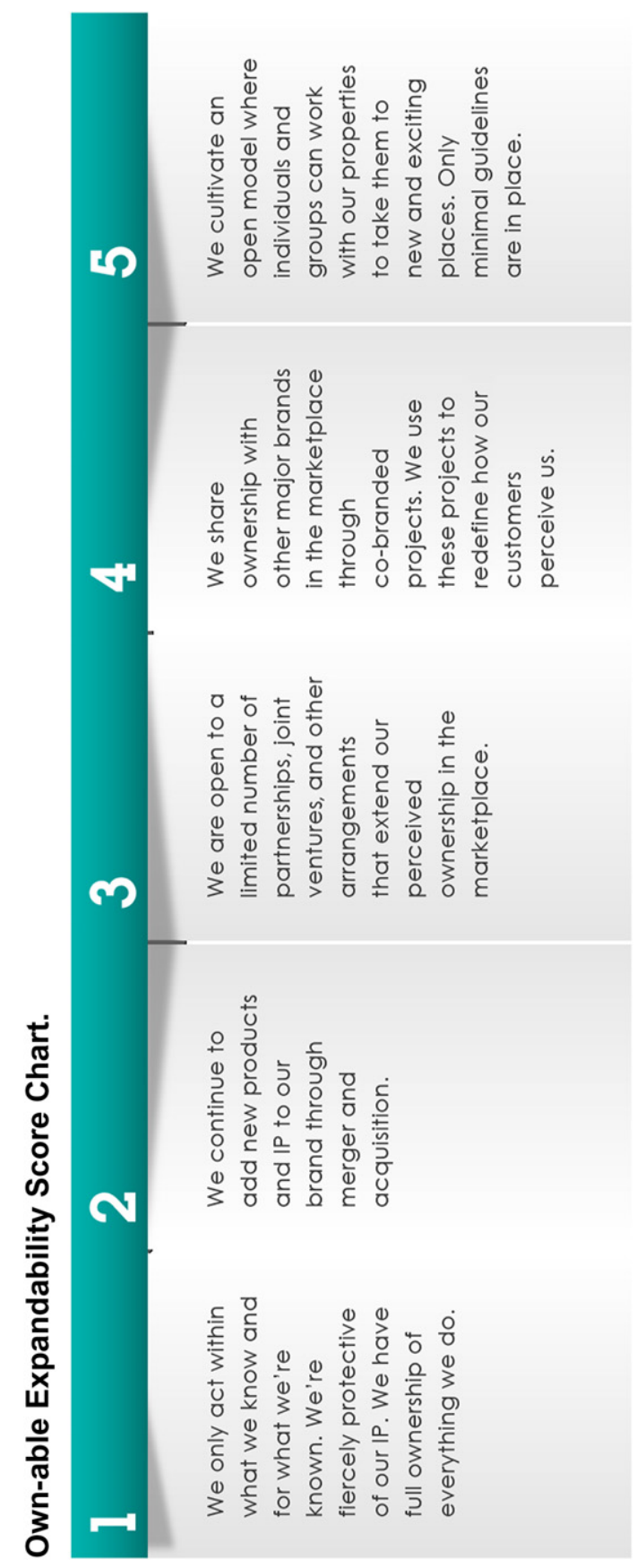


Base your score on how much you retain control and how you intend to fascinate consumers. There are no right or wrong answers. Some brands will feel that ownership is central to ownability; others will see ways to co develop new arrangements. Choose the number that best describes how your brand puts its mark on everything you do. We'll come back and get this number after the next chapter. If you've stuck with me so far, give yourself a pat on the back! You're now grown by a leap year in terms of the knowledge you have of your brand. Next, we're going to put this all together. 